Saari, A. (2019). Out of the box: behaviourism and the mangle of practice. Discourse: Studies in the Cultural Politics of Education, 40(1), 109-121.

\title{
Out of the Box: Behaviourism and the mangle of Practice
}

Antti Saari

University of Tampere, Faculty of education

Antti.w.saari@staff.uta.fi

\begin{abstract}
Although often labelled obsolete and ethically dubious, 20th-century behaviourist principles of learning have been central to the development of instructional technology and the design of modern learning environments. Using Andrew Pickering's philosophy, this article addresses behaviourism as a mangle of practice to highlight the conceptual and nonhuman agency involved in research on learning, and to analyse how these forms of agency allow scientific knowledge to travel from experimental research settings to teaching.
\end{abstract}

Keywords: psychology of learning, science and technology studies, behaviourism, educational research

\section{Introduction}

Who wants to be a behaviourist nowadays? Contemporary theories of learning in the fields of education and psychology attribute a negative connotation to the term 'behaviourist'; therefore, few educators and researchers wish to be associated with the term. In the origin narratives of many learning theories since the late 20th century, behaviourism has often functioned as the other through which theoretical positions are defined (see e.g. Richardson, 1996; Ertmer \& Newby, 2013). 
Saari, A. (2019). Out of the box: behaviourism and the mangle of practice. Discourse: Studies in the Cultural Politics of Education, 40(1), 109-121.

Critiques of behaviourism in theories of learning signal not only the need to construct otherness but also the sweeping influence of behaviouristic theories of learning and their applications. B. F. Skinner, the figure most strongly associated with the term, is widely hailed as the most influential psychologist of the 20th century, having helped to establish the status of psychology as an experimental science and its practical value in behaviour management practices. His theories of learning have had an immense impact on education.

Behaviourism was also a precursor to many material and technological features of later research on learning and its applications in education; it paved the way for the hegemony of the 'learning sciences' in Anglophone education, and for forms of ICT and the design of 'learning environments’(Taubman, 2009; Williamson, 2017).

The following analysis is not a defence of behaviourism as a theory of learning or human agency, nor is it another rebuttal, but rather an examination of how experimental research, (i.e. the manipulation and systematic observation of variables in a controlled environment to explain the causes of their interaction) is made relevant for education (see Shapin \& Schaffer 1985; Callon, Lascoumes \& Barthe, 2009).

I discuss the history of behaviourist research of learning and its applications in education as a ‘mangle of practice’ (Pickering, 1995). In Andrew Pickering’s theory of science and technology, the mangle refers to the way conceptual, social and material aspects of research are made to operate together as a machinic whole. This underscores the performative aspect of experimental research. Rather than mere passive representation, experimental research is understood as an intervention in and construction of the human and non-human world (Pickering, 1995, pp. 5-9). 
Saari, A. (2019). Out of the box: behaviourism and the mangle of practice. Discourse: Studies in the Cultural Politics of Education, 40(1), 109-121.

My analysis of Skinnerian experimental research highlights two prominent topics in STS and its uses in educational research. First is the focus on the socio-material conditions of 'making facts travel' (Howlett \& Morgan, 2010) beyond their immediate site of production. Making educational research relevant in spaces of education policies and classrooms does not involve just the simple application of research findings as facts. Instead, it requires the design and management of conceptual as well as material relations (Gorur, 2013, 2015a; Fenwick \& Edwards, 2010; Saari, 2012).

The second relevant topic is the crucial role of non-human agency in science, technology and society (Haraway, 2009). A central starting point in STS is refraining from making an $a$ priori distinction between human and the non-human, and instead looking at the emergent, local distributions of agency. In education, social media, textbooks, assessments and tests, as well as classroom walls assume agency by translating, resisting and enabling pedagogical practices, while enhancing, inhibiting and/or reconfiguring human agency (see e.g. Christie \& Bloustien, 2010; Waltz, 2004).

In this paper, the themes of travelling facts and non-human agency are analysed in Skinnerian behaviourism. I address two research questions. First, how are conceptual and non-human forms of agency distributed and controlled in Skinnerian experimental research on learning? Second, how does the 'tuning' of agency make experimental research relevant to education?

\section{Mangle of practice and the dance of agency in research}

For Andrew Pickering, a central condition of opening vistas for problematizing agency in scientific research is the shift from a 'representational idiom' to a 'performative' one (Pickering, 1995, p. 5; Pickering, 2010, pp. 380-381). In this, he follows philosophers of 
Saari, A. (2019). Out of the box: behaviourism and the mangle of practice. Discourse: Studies in the Cultural Politics of Education, 40(1), 109-121.

science such as Ian Hacking (1983), who highlighted that research is not only about 'representing' but also involves 'intervening' in the object of research, and sometimes even constructing objects that would not otherwise exist. Pickering (1995) also draws from Deleuze and Guattari’s (2004) concepts of machinic assemblage and becoming to draw attention to the decidedly immanent and emergent characteristics of agency in science and technology.

Pickering condenses the ideas of performativity in the concept of the mangle. Mangling refers to 'machinic' operations in science and technology, where human and material elements are 'tuned' to each other to operate as a concerted whole. In this process, these elements assume immanent forms of agency as they accommodate and resist each other's influence (Pickering, 1995, pp. 21-26). Through this ‘dance of agency’, science is produced like laundry being pushed through a mangle press (Pickering, 1995).

The science that for Pickering best exemplifies the mangle of practice is cybernetics, especially the more experimental and unruly areas that combine performing arts, neurosciences, engineering and religion (Pickering, 2010). According to Pickering (2008, p. 12), cybernetics is 'engineering in the thick of things', open-ended experimentation with what is possible without restricting scaffolds or prostheses of scientific disciplines and theories. Furthermore, cybernetics openly discards representational idioms, as it highlights the artifice of constructing technological apparatuses and examining their forms of agency. A poignant example of such an artifice is the homeostat, a cybernetic device consisting of different units that turn variable electrical inputs from other units into outputs. These units constantly react to each other's currents, meaning the whole system can repeatedly reconfigure itself to reach homeostasis. For Pickering, this highlights the dance of agency as being decidedly non- 
Saari, A. (2019). Out of the box: behaviourism and the mangle of practice. Discourse: Studies in the Cultural Politics of Education, 40(1), 109-121.

human and emergent; it also underlines cybernetics' focus on construction and performance, rather than mere representation (Pickering, 2010, pp. 102-104).

Outside Pickering’s own oeuvre, the idea of the mangle has been mobilized to study topics as diverse as information systems (Olohan, 2011), and environmental planning (Franklin, 2008). Although it has been relatively marginal in the study of education, the theme of the mangle has opened up means of conceptualizing the distribution of agency between humans and nonhuman elements across topics ranging from instructional technology to the construction of statistical data in governing education (Gorur, 2015b; Serder \& Ideland, 2016; Waltz, 2004).

In my analysis of behaviourism as a mangle of practice, I highlight performative aspects of experimental research and its applications. Instead of a stable network of theories, concepts and objects, behaviourism is seen as a moving and constantly evolving target, a Ship of Theseus that changes many of its constituting elements in time, yet which retains its central machinic relations. In this process of change, 'research' flows into 'practice'; theories and concepts from different disciplines, such as education, physiology and psychology, are transferred into one another in an open-ended process. Animals can be replaced with humans, and Skinner boxes with classrooms, teaching machines and scrambled books.

\section{Behaviourism}

In the popular imagination, behaviourism refers to conditioning animals and humans through stimulus programs that enhance or extinguish behavioural responses. As such, it evokes images of Pavlov's dogs or Skinner's ping pong-playing pigeons. Behaviourism is also remembered for its bracketing or outright denial of consciousness and free will (see e.g. Skinner, 1971). Moreover, some of its research methods - such as those deployed in 
Saari, A. (2019). Out of the box: behaviourism and the mangle of practice. Discourse: Studies in the Cultural Politics of Education, 40(1), 109-121.

Watson's infamous studies with little Albert (Watson \& Rayner, 1920) - have been ethically questionable (Todd, 1994). Therefore, the behaviourist tradition has always been highly controversial. Mid-20th-century philosophical critiques - most notably those of Chomsky (1959) and Taylor (1964) - questioned behaviourism as a philosophically viable approach to explaining human behaviour. Later, constructivist and humanistic learning theories declared behaviourism an utterly mechanistic and reductionistic stance that does not respect individual agency and meaning making (see e.g. von Glasersfeld, 1995).

Although sometimes reduced to the bestiary of obsolete and dubious theories of learning, behaviourism was, in the early to mid-20th century, a widely proliferated set of theories for explaining animal and human behaviour. It was also a platform for behaviour management programs in educational and therapeutic institutions. As such, behaviourism was etched indelibly through three central drivers in American human sciences and politics. First, behaviourism responded to political and scientific progressivism that sought practical solutions to a society characterized by rapid technological and industrial change and urbanization. Many of these hopes were laid at the feet of educational institutions. Second, it responded to calls to provide an empirical outlook on human behaviour and managing social change. Third, behaviourism was connected to the widespread call to explain human behaviour in terms derived from physiology and biology, and the biopolitical programs for applying such ideas (Mills, 1998, pp. 23-25). These three drivers were linked to the rapid rise of experimental (and quasi-experimental) methods in the social and behavioural sciences (Smith, 2002). Controlling and measuring variables was seen not only as the gold standard of objective research but also as a way to solve practical questions of managing societal institutions, such as schools, factories, and economic markets. In fact, the whole of society 
Saari, A. (2019). Out of the box: behaviourism and the mangle of practice. Discourse: Studies in the Cultural Politics of Education, 40(1), 109-121.

would now be seen as an enormous laboratory that could be meticulously measured and controlled (Oakley, 2000).

Experimental research in psychology assumed many forms in the late 19th and early 20th centuries. The prominent traits of behaviourist research were conducting a single research study under meticulously controlled laboratory conditions and limiting the scope of behaviour to a few measurable variables (Danziger, 1990). Skinner condensed the idea of thorough control in his famous principle of operant conditioning. For Skinner, an organism always acts in order to achieve a certain balance with its environment, such as in terms of satisfying needs. Such behaviour induces changes in its environment, which in turn produces new kinds of 'stimuli' for the organism, to which it then responds. This forms a loop that can be viewed as a closed system and that can be observed, measured and controlled in experimental conditions (Skinner, 1957, pp. 103-104; Skinner, 1961, pp. 59-99). Skinner insisted that this idea could be broadened to a general theory of behaviour and learning applicable to behaviour management in schools, at work or in the army (Skinner, 1957).

\section{Conceptual agency}

Skinner conducted his experiments with animals, but claimed relevance for explaining human behaviour. Despite the widespread topos of comparing the 'human' and the 'animal' in western philosophy, the relevance of experimental studies on animals for understanding human action in mainstream psychology and education was far from obvious. Prior conceptual boundary work was required to bring human and animal action to a mutual plane of comparison. In this, concepts assumed an agency in their patterns of emergence and repetition, and paved the way for transferring other concepts and research practices. 
Saari, A. (2019). Out of the box: behaviourism and the mangle of practice. Discourse: Studies in the Cultural Politics of Education, 40(1), 109-121.

Pickering claimed that when taking models from old conceptual systems to a new one, the first phase involves establishing a 'bridgehead that tentatively fixes a vector of cultural extension to be explored' (Pickering, 1995, pp. 115-116). Such a bridgehead was late 19th and early 20th-century research on animal learning and intelligence. The central boundary concepts for understanding humans through ethology, physiology and animal psychology were 'organism' and 'behaviour', as they allowed for the concepts of 'intelligence' and 'learning’ to be transferred to studying human behaviour (Danziger, 1997). For example, a pioneer in animal psychology, George Romanes (1882, pp. 14-15), saw ‘intelligence’ as an adaptive principle that characterizes the 'behaviour' of 'organisms' from protozoa and insects to primates. This formed a basis on which Skinner could build his conceptual apparatus, and paved the way to forging a connection between what was discovered in animal behaviour and how this could assume relevance for understanding human behaviour.

With these initial conceptual bridgings in place, experimenting with animals could, in the early psychology of learning, be used not only to develop knowledge of animal learning per se, but also to study human learning indirectly through its (assumedly) simpler forms (Danziger, 1997). For example, E. L. Thorndike (1898) studied how cats and chickens 'learn' to find their way out of small mazes. These results were, in turn, applied in his textbook on education psychology (Thorndike, 1912/1999) to characterize the basic 'laws’ of learning. Thorndike viewed the difference between 'lower organisms', animals and humans not as qualitative and decisive but as merely gradual, as in degrees of complexity. Similar arguments were made in Watson's famous behaviourist manifesto (1913), and then by Skinner in Behaviour of Organisms (1938). The concepts of organism and behaviour opened pathways to other concepts, and to ways of arguing about them in relation to animals and humans. Furthermore, they in part operated as a subsequent bridgehead for transferring 
Saari, A. (2019). Out of the box: behaviourism and the mangle of practice. Discourse: Studies in the Cultural Politics of Education, 40(1), 109-121.

certain material and technological elements from experimental studies on animals to education spaces.

\section{Tuning the box}

Characteristic of the behaviourist research tradition is the prominent role of animals and mechanical apparatuses, epitomized by the famous Skinner box used to study the basic laws of behaviour. This is also where the aforementioned concepts of organism, behaviour and learning are brought together with material and technological elements. The Skinner box is a ventilated and lit aluminium crate divided into two sections. On one side, there is the animal - small and easily controllable, often a rat or a pigeon. In front of the animal is a plate wired to a sensor and a plotter. The wall has a food-dispensing mechanism connected to the sensor (Skinner, 1957).

As such, this setting satisfied Skinner’s criteria for experimental research. First, there has to be a thoroughly standardized space that isolates the organism from its environment and limits the scope of its action. It must also be able to isolate the controllable and repeatable part of behaviour in the animal (Skinner, 1957, p. 344). The experiment begins by placing a hungry animal inside the box. Through trial and error, the animal 'learns' that by manipulating (pecking, pushing) the dispensing mechanism, it can receive nutrition to satisfy its hunger. Hunger here is the initial stimulus that triggers behaviour, and the box conditions it further by reinforcing certain responses. The sensors and plotters register the change in behaviour by automatically inscribing a graphic representation of it (Skinner, 1957, 1975).

The operation of the box highlights Pickering's notion of 'tuning' that takes place in research. In the mangle, the animal and the material and technological elements are fitted to each other. 
First, the material and technological elements trace the features of the animal. The box is built to suit the size and behaviour of the organism; thus, a pigeon demands a different kind of box to a cat or a lab rat. Furthermore, the mechanical setting is adapted to the animal's needs, as it provides nutrition. In other words, animal species exhibit 'resistance', into which other parts of the mangle must tune. Yet the mangle also 'tunes' the animal by narrowing the spectrum of possible behaviour, such as disabling communication with other members of the species. Furthermore, the rats used in the Skinner box experiments were not just any kind of rodents; they were systematically bred to have certain characteristics that suited experimental requirements (Skinner, 1975).

The material and animal elements of the behaviourist mangle (i.e. the walls and mechanisms of the box, the animal) exemplify the immanent and dispersed character of agency in scientific research. As in Barad's (2003) notion of 'intra-action', it takes at least two elements to create action. In the case of the Skinner box, behaviour does not just flow from 'inside' the animal; rather, it is a composite effect of the mangle (i.e. the walls and the dispensing mechanism as well as animal hunger and alertness). This makes it impossible to allocate agency to just one element, let alone to claim that material and technological elements are merely passive recipients or conduits of animal agency. These animals and their behaviour would not exist as such if not for the social and technological elements of the laboratory experiment that 'educate' them by disciplining their behaviour (see also Haraway, 2008, pp. 70-75, p. 281; Haraway, 2009).

Now we have the initial key ingredients of the behaviourist mangle: it is a machinic assemblage of conceptual, technological and material elements that divides behaviour into 
Saari, A. (2019). Out of the box: behaviourism and the mangle of practice. Discourse: Studies in the Cultural Politics of Education, 40(1), 109-121.

controlled constituents and tunes it to form a closed loop between stimuli and responses. Next, I will look at how this mangle was retuned in educational settings.

\section{Machinic teaching and learning}

Despite constituting a closed circuit of feedback, the behaviourist mangle was also a relatively open code that could be subsequently re-worked, re-tuned and scaled up outside of strictly experimental conditions. Skinner and his colleagues were well aware of the possibilities of spreading the notion of behaviour management outside the box. Some of Skinner’s most imaginative applications did not catch on, such as the wartime Project Pigeon - guided missiles with pigeons inside to steer them to their target (Skinner, 1957, pp. 426.01426.18) - or the ventilated 'Air Crib' - a climate controlled, furnished box with walls and a window - for babies (Skinner, 1957, pp. 419-426), which enjoyed only a brief surge of popularity. However, ideas relating to behaviour management were spread successfully into small experimental communities inspired by Skinner’s Walden Two, a utopia of governing societies with behaviourist principles. Furthermore, the programs of token economy (i.e. treating patients with schizophrenia with behaviourist reinforcement programs) grew in popularity in mental institutions in the 1960s and 1970s (Rutherford, 2009).

All of these iterations of the behaviourist mangle elaborated on notions of behaviour management: breaking behaviour down to simple elements, controlling them with reinforcement through the meticulous design of the material environment and forming closed feedback loops consisting of these elements. As an iteration of this code in education, I will next examine early instructional technology in the form of teaching machines and programmed instruction. 
Saari, A. (2019). Out of the box: behaviourism and the mangle of practice. Discourse: Studies in the Cultural Politics of Education, 40(1), 109-121.

Sidney Pressey invented the teaching machine in the 1920s. Pressey (1926) constructed a device that resembled a common typewriter; such a machine would 'teach' in the sense of giving a set of multiple choice questions on a sheet paper and requiring the pupil to push buttons (a to d) corresponding to their choice of answer. If the answer was wrong, the pupil would try again until she or he provided the right answer; they would then be guided to the next item. Skinner elaborated on Pressey’s invention by aligning it with the theory of operant conditioning and technological solutions that enabled more sophisticated variations of conditioning programs. In The Technology of Teaching (1968), he introduced various teaching machines and the programs they could run. The technical finesse varied from Pressey-like machines to more complex classrooms for self-study; the program could incorporate a simple linear set of items or could have a branching nature that allowed for thousands of different variations. The subject content could be anything from languages to history to mathematics.

What all of these machines and programs had in common was the logic of operant conditioning. The program would present the pupil with a stimulus and give a limited range of possible responses. Depending on the response, the program would guide the pupil to new sets of tasks (Skinner, 1968). Here, we can see how the behaviourist mangle could vary many of its technical, material and 'biological' characteristics without losing its general character of managing behaviour and distributing agency in a closed system. As the program unfolds, what can be aligned with Pickering’s (1995) 'dance of agency’ occurs, where humans and technology take turns influencing each other.

Taking the behaviourist mangle from the Skinner box to the teaching machine opened up conceptual pathways between behaviourist psychology, theories of teaching and computer 
Saari, A. (2019). Out of the box: behaviourism and the mangle of practice. Discourse: Studies in the Cultural Politics of Education, 40(1), 109-121.

programming. This resulted in a new area within instructional planning called 'programmed instruction', the art of designing educational behaviour management programs with the help of mechanical devices (see e.g. Stolurow, 1961), which would then evolve into modern instructional technology (Reiser, 2001; Taubman 2009; Williamson 2017).

The teaching machine illustrates how the boundaries of behaviourist experimental research and its application dissolve, as an apparatus that studies and records behaviour can easily be turned into a machine that 'teaches' and 'grades'. Therefore the teaching machine also shows how behaviourist 'facts' about learning can travel and be valid in education. Bruno Latour (1983) noted that to make scientific research relevant, one must move the laboratory walls into the world; this underlines that it is always not so much an adequate 'representation' of 'nature' that makes science 'work', but the performative mobilization and reworking of elements in the research setting itself.

\section{Further iterations in education}

Skinner (1968, pp. 20-21) claimed that, ultimately, all education could be conceived of as an interchange of stimuli and responses, and that the elements of the school class could be seen as a set of operants that could be harnessed for the purposes of behaviour management. Moreover, he claimed that to be more effective, the school should be designed to be more like an experimental laboratory, reducing its complexity and increasing control (Skinner, 1968, p. 19). This view gained traction in both mainstream educational research and applications to teaching. I will next look at selected cases of iterations of the behaviourist mangle (i.e. ways in which agency is distributed and tuned in similar ways across different education sites). 
Saari, A. (2019). Out of the box: behaviourism and the mangle of practice. Discourse: Studies in the Cultural Politics of Education, 40(1), 109-121.

By the advent of World War II, behaviourism had gained a significant position in the American psychology of learning. During the war, many notable psychologists trained in behaviourism, such as Robert Gagné, Robert Mager, Lawrence Stolurow, Robert Glaser and N. L. Gage, would later play a definitive role in Anglophone educational research. They designed techniques of meticulous task analysis that broke behaviour down to its smallest constituents and combined them to meet specific aims defined in observable behaviour. Task analysis was seen as necessary in annexing human behaviour to complex man-machine systems such as anti-aircraft guns (Noble, 1991; Tröhler 2013).

These wartime innovations provided an impetus for experimenting with the analogy between military man-machine systems and educational spaces, while introducing concepts from AI, cybernetics and systems theory (Taubman, 2009, pp. 164-168). One such concept was feedback, a circuit of different sensors, effectors and pathways of energy or information that formed an autonomous system. The concept of feedback was both a theoretical representation of the functioning of living organisms and a model for designing technological systems (Kline, 2015; Pickering, 2010).

The ubiquity of the feedback model opened up a way of designing not only programmed instruction but also broader educational spaces based on behaviourist principles. In the early 1960s, central categories, concepts and models of behaviourist learning theory were bridged into researching teaching. In the influential Handbook of Research on Teaching, Skinner's former assistant N. L. Gage wrote of the new 'machine paradigm’ in educational research:

The design of teaching machines was originally guided by the characteristics and processes of human learners. It is conceivable that this approach can be reversed, i.e., 
Saari, A. (2019). Out of the box: behaviourism and the mangle of practice. Discourse: Studies in the Cultural Politics of Education, 40(1), 109-121.

that the design of research on human teachers can be guided by the characteristics of teaching machines. (Gage, 1963, p. 129)

Gage then proceeded to map the functions of the teaching machine-learner feedback system to that of a teacher-learner system. Some of these (such as pacing and branching questions and answers) may take place inside the 'teacher's "mind"' and others in the 'pupil's vocal or writing organs and equipment' (Gage, 1963, pp. 129-132.) It is evident that the 'machine paradigm' is no longer reducible to interaction between a human and a teaching machine, but rather denotes a way of analysing and constructing different parts of interaction in the learning process as forming a closed feedback system.

The mappings across teaching machines and more traditional teaching models were not reduced to conceptualizing and designing educational research as they also involved planning and evaluating teaching. Robert Mager’s famous book Preparing Instructional Objectives (1962) focuses on the way curriculum planners and teachers could define 'meaningful' objectives. Tellingly, the book was first published as Preparing Objectives for Programmed Instruction, and refers to 'instructors' and 'programmers', and 'courses' and 'programs', interchangeably. The book instructed the reader to define instructional objectives in precise terms of 'terminal behaviour' so that instruction could be effectively steered towards them. Moreover, this would aid in designing objective tests that measure this behaviour. Through behavioural objectives, then, the book imagines a closed system where planning, implementing and evaluating instruction flow into one another in a controlled fashion, and where constant adjustments are made (Mager, 1962). 
Curiously, the book itself assumes an agency of a teaching machine and its program; it is a so-called 'scrambled book'. The scrambled book was a novel application of behaviourist ideas of programmed instruction. Rather than reading the book linearly from beginning to end, the study path branches in multiple directions, moving back and forth in the book. Moreover, the book constantly tests and gives feedback to the reader (Lawson, Burmester \& Nelsox 1960).) Each chapter of Mager's book presents study material and then 'tests' the reader by presenting multiple-choice items. Depending on the given answer, the book then gives immediate feedback and directs the reader to another page to either start the next study sequence or to go back and revise the material. Thus, the book-machine forms a feedback loop by constantly adjusting to the 'needs' of the reader (Mager, 1962).

These examples serve to highlight how the elements of the mangle in Skinner boxes and teaching machines could be re-tuned in planning and constructing research and instruction in general. They could also be easily connected to larger machinic systems of governing education. In post-World War II America, and especially after the Sputnik shock, education policies were increasingly imagined as a controlled system forming a feedback loop of curriculum planning, goal setting, implementation and evaluation. The learning sciences had a central role in formulating precise goals in behavioural terms, teaching as behaviour management and testing and evaluation as measuring behavioural outcomes (Taubman, 2009; Tröhler 2013). In this way, the behaviourist mangle found its role in the broader 'sociocyborgs' (Pickering, 1995, p. 195) of education, assemblages of multiple people, material spaces and technological devices, as well as management programs with their concepts, imputed aims and forms of evaluation. 
Scaling from the simple operation of a Skinner box or a teaching machine to broader behaviour analysis and the control of educational institutions, the mangle of behaviourist research helped in establishing centres of calculation that standardized and measured education, making possible the control of the few over the many. By the end of the $20^{\text {th }}$ century, it would reconfigure parts of itself by dispensing with the concepts of external behaviour and replacing them with internal cognitive and information processing ones. This was discernible in e.g. the discourses of psychology of learning, curriculum planning, and instructional design. However, many other parts - focusing on measurable tasks and outcomes, and designing learning environments as controlled systems - remained (Taubman, 2009, pp. 160-171).

\section{Conclusions}

The analysis of the behaviourist mangle highlights the performative characteristics of experiments. While behaviourist research purportedly represented the universal laws of learning, the analysis of the mangle brings out the performativity and craftsmanship of experimentation: the intervention in, and construction of, learning in its research environments. From this perspective, two key outcomes of the analysis can be advanced. First, the focus on performativity reveals the multiple forms of agency at play in experimental research on learning. As the case of the Skinner box exemplifies, experimental research not only reserves agency for humans but inevitably for conceptual, material and technological elements, and sometimes animals as well. These forms of agency are tuned together to form a machinic whole, which is responsible for the systematic production of experimental data about learning. 
Second, the conceptual, material and organic forms of agency determine how scientific facts about learning can travel and be valid across different sites. There is no single interface between research and practice. Research is not made applicable just by taking up research results, nor by solely applying scientific concepts and theories in practice. Instead, for research to be applicable, a plethora of different forms of agency should be made isomorphic between the laboratory and the learning environment. First of all, the central concepts of behaviourism tapped into the central drivers of American political and educational imaginaries: the demand of prediction and control of social change and the belief of science and technology in enabling it. Moreover, applying experimental research in early designs of instructional technology required that organic and material forms of agency similar to those of the Skinner box be tuned together in the teaching machine to form a closed system with controllable and measurable elements. It is then the smooth and predictable functioning of this machinic whole that determines whether behaviourist theories of learning really 'work' in education.

In a limited sense, behaviourism did indeed work. Within the confines of simple teaching machines, it constructed learning along the lines of behaviourist theory. But while the ideas and practices of thorough control undoubtedly contributed to behaviourism's wide appeal in education, they also contributed to its failures in larger educational reforms. Those phenomena that were not annexable to the mangle (e.g. pupils' unpredictable actions, learning material not subjected to control, teachers' improvised instruction) were either neglected or regarded as sources of error impeding the proper functioning of the system. Despite repeated attempts to transform unruly education spaces in the image of a closed system of behaviour control, schools could never efface their complex and unpredictable character (Cuban, 2013; Robins \& Webster 1990). 
Despite such evident failures, elements recognizable from the behaviourist mangle are again on the ascent. Today, there is a firm belief in the practical value of experiments and quasiexperiments aimed at measuring visible, quantifiable 'behaviour' (although often not in laboratory settings) in different areas, such as education, behavioural economics and public policy (John, 2017). ‘Evidence-based’ discourses claim that such scientific knowledge accurately represents human behaviour and enables the construction of management practices that 'work'. Behaviour management is back in schools as a viable, and allegedly effective, teaching method, creating an air of technical simplicity and predictability (see e.g. Maag, 2018). Although the behaviourist paradigm has been labelled obsolete in many dominant discourses of learning sciences and instructional technology, at the level of material and social practices there is an obvious continuity between behaviourist mangle and contemporary socio-material practices of instructional technology. While employing theories and concepts of positive psychology ${ }^{1}$, rapidly developing mobile technology now produces an array of simple behaviour reinforcement apps that aid in disciplining, measuring, and documenting behaviour in classrooms and giving immediate feedback (Williamson 2017, pp. 443-444). Moreover, there is a noteworthy convergence of AI, programming and the learning sciences in the form of 'deep learning' and in the design and use of software programs that have an unforeseen ability to constantly reconfigure themselves in an open-ended process. These programs are currently used in constructing information systems that challenge, enhance and ‘individualize’ learning in education (Peters, 2017).

\footnotetext{
${ }^{1}$ Martin Seligman, a central figure in the development of positive psychology, started his career in behaviourist laboratory experiments on animals (see e.g. Seligman, Maier \& Greer, 1968).
} 
Looking at these developments of research and technology as iterations of a mangle can aid us in recognizing that their possible relevance for education lies not only in representation but in the design and tuning of different forms of conceptual and non-human agency. This points to the fact that applying educational research inevitably involves conquering and transforming those spaces where such knowledge is applied; disciplining, stabilizing and streamlining the conceptual and material complexities of education (Gorur, 2015b; Saari, 2012). In sum, our focus should be directed to the prevalent 'politics of experimentation' (Pickering, 2008, p. 13) - that is, the way research practices and their applications are opening up and delimiting a set of possible forms of agency and developing their interplay. Furthermore, we should investigate how experimental research may limit our understanding of learning, the activities in a classroom and evaluation practices in the name of accurate ‘representations’ of human learning.

\section{References}

Barad, K. (2003). Posthumanist performativity: Toward an understanding of how matter comes to matter. Signs: Journal of Women in Culture and Society, 28(3), 801-831.

Callon, M., Lascoumes, P. \& Barthe, Y. (2009). Acting in an uncertain world: An essay on technical democracy. Cambridge, Mass: MIT Press.

Chomsky, N. (1959). Review of verbal behaviour. Language, 35, 26-58.

Christie, E. \& Bloustien, G. (2010). I-cyborg: Disability, affect and public pedagogy.

Discourse: Studies in the Cultural Politics of Education, 31(4), 483-498. 
Saari, A. (2019). Out of the box: behaviourism and the mangle of practice. Discourse: Studies in the Cultural Politics of Education, 40(1), 109-121.

Cuban, L. (2013). Inside the black box of classroom practice: Change without reform in American education. Cambridge: Harvard Education Press.

Danziger, K. (1990). Constructing the subject: Historical origins of psychological research. Cambridge: Cambridge University Press.

Danziger, K. (1997). Naming the mind: How psychology found its language. London: Sage.

Deleuze, G. \& Guattari, F. (2004). A thousand plateaus: Capitalism and schizophrenia. New York: Continuum.

Ertmer, P. A. \& Newby, T. J. (2013). Behaviourism, cognitivism, constructivism: Comparing critical features from an instructional design perspective. Performance Improvement Quarterly, 26(2), 43-71.

Fenwick, T. \& Edwards, R. (2010). Actor-network theory in education. New York: Routledge.

Franklin, A. (2008). A choreography of fire: A posthumanist account of Australians and eucalypts. In A. Pickering \& K. Guzik (Eds.), The mangle in practice: Science, society and becoming (pp. 17-44). Durham: Duke University Press.

Gage, N. L. (1962). Paradigms for research on teaching. In N. L. Gage (Ed.), Handbook of research on teaching (pp. 94-141). Chicago: Rand McNally \& Co. 
Saari, A. (2019). Out of the box: behaviourism and the mangle of practice. Discourse: Studies in the Cultural Politics of Education, 40(1), 109-121.

von Glasersfeld, E. (1995). Radical constructivism: A way of knowing and learning. London: Falmer Press.

Gorur, R. (2013). My school, my market. Discourse: Studies in the Cultural Politics of Education, 34(2), 214-230.

Gorur, R. (2015a). Situated, relational and practice-oriented: The actor-network theory approach. In K. Gulson, M. Clarke \& E. Bendix Petersen (Eds.), Education policy and contemporary theory (pp. 87-98). London: Routledge.

Gorur, R. (2015b). Producing calculable worlds: Education at a glance. Discourse: Studies in the Cultural Politics of Education, 36(4), 578-595.

Hacking, I. (1983). Representing and intervening: Introductory topics in the philosophy of natural science. Cambridge, MA: Cambridge University Press.

Haraway, D. (2008). When species meet. Minneapolis: University of Minnesota Press.

Haraway, D. (2009). Becoming-with-companions: Sharing and response in experimental laboratories. In T. Tyler \& M. Rossini (Eds.), Animal encounters (pp. 115-136). Leiden: Brill.

Howlett, P. \& Morgan, M. S. (Eds.). (2010). How well do facts travel? The dissemination of reliable knowledge. Cambridge/New York: Cambridge University Press. 
Saari, A. (2019). Out of the box: behaviourism and the mangle of practice. Discourse: Studies in the Cultural Politics of Education, 40(1), 109-121.

John, P. (2017). Behavioural science, randomised evaluations and the transformation of public policy. In J. Pykett, R. Jones \& M. Whitehead (Eds.) Psychological governance and public policy: Governing the mind, brain and behaviour (pp. 133-152). London: Routledge.

Kline, R. R. (2015). The cybernetics moment: Or why we call our age the information age. Baltimore: Johns Hopkins University Press.

Latour, B. (1983). Give me a laboratory and I will raise the world. In K. Knorr-Cetina \& M. Mulkay (Eds.), Science observed: Perspectives on the social study of science (pp. 141-170). London: Sage.

Lawson, C. A., Burmester, M. A., \& Nelsox, C. H. (1960). Developing A scrambled book and measuring its effectiveness as an aid to learning natural science. Science Education, 44(5), 347-358.

Maag, J. W. (2018). Behavior management: From theoretical implications to practical applications. Boston: Cengage Learning.

Mager, R. S. (1962). Preparing instructional objectives. Palo Alto: Fearon Publishers.

Mills, J. A. (1998). Control: A history of behavioural psychology. New York: NYU Press.

Noble, D. D. (1991). The classroom arsenal: Military research, information technology, and public policy. New York: Taylor \& Francis. 
Saari, A. (2019). Out of the box: behaviourism and the mangle of practice. Discourse: Studies in the Cultural Politics of Education, 40(1), 109-121.

Oakley, A. (2000). Experiments in knowing. Gender and method in the social sciences. Cambridge: Polity Press.

Olohan, M. (2011). Translators and translation technology: The dance of agency. Translation Studies, 4(3), 342-357.

Peters, M. (2017). Deep learning, education and the final stage of automation. Educational Philosophy and Theory, 1, 1-5. Retrieved from http://www.tandfonline.com/doi/abs/10.1080/00131857.2017.1348928?needAccess=true

Pickering, A. (1995). The mangle of practice: Time, agency, and science. Chicago: University of Chicago Press.

Pickering, A. (2008). New ontologies. In A. Pickering \& K. Guzik (Eds.), The mangle in practice: Science, society and becoming (pp. 1-14). Durham: Duke University Press.

Pickering, A. (2010). The cybernetic brain: Sketches of another future. Chicago: University of Chicago Press.

Pressey, S. (1926). A simple apparatus which gives tests and scores - and teaches. School and Society, 23(586), 373-376.

Reiser, R. (2001). A history of instructional design and technology. Part II: A history of instructional design. Educational Technology, Research \& Development, 49(2), 57-67. 
Saari, A. (2019). Out of the box: behaviourism and the mangle of practice. Discourse: Studies in the Cultural Politics of Education, 40(1), 109-121.

Richardson, V. (1996). From behaviourism to constructivism in teacher education. Teacher Education and Special Education, 19(3), 263-271.

Robins, K., \& Webster, F. (1990). The technical fix: Education, computers and industry. Basingstoke: Macmillan.

Romanes, G. A. (1882). Animal intelligence. London: Kegan Paul.

Rutherford, A. (2009). Beyond the box: B. F. Skinner's technology of behaviour from laboratory to life, 1950s-1970s. Toronto: University of Toronto Press.

Saari, A. (2012). The map is the territory - Educational evaluation and the topology of power. European Educational Research Journal 11(4), 586-600.

Seligman, M.E.P., Maier, S.E. \& Geer, J.H. (1968). Alleviation of learned helplessness in the dog. Journal of Abnormal Psychology 73 (3), 256-262.

Serder, M., \& Ideland, M. (2016). PISA truth effects: the construction of low performance. Discourse: Studies in the Cultural Politics of Education, 37(3), 341-357.

Shapin, S. (1985). Leviathan and the air-pump: Hobbes, Boyle, and the experimental life. Princeton, N.J: Princeton University Press.

Skinner, B. F. (1938) Behaviour of organisms. Oxford: Appleton-Century. 
Saari, A. (2019). Out of the box: behaviourism and the mangle of practice. Discourse: Studies in the Cultural Politics of Education, 40(1), 109-121.

Skinner, B. F. (1957). Cumulative record. New York: Appleton-Century-Crofts.

Skinner, B. F. (1961). Why we need teaching machines. Harvard Educational Review, 31(4), 377-398.

Skinner, B. F. (1968). The technology of teaching. New Jersey: Prentice Hall.

Skinner, B. F. (1971). Beyond freedom and dignity. New York: Penguin Books.

Skinner, B. F. (1975). The shaping of phylogenetic behaviour. Journal of Experimental Analysis of Behaviour, 24, 117-120.

Smith, L. D. (2002). On prediction and control: B. F. Skinner and the technological ideal of science. In W. E. Pickren \& D. A. Dewsbury (Eds.), Evolving perspectives on the history of psychology (pp. 255-272). Washington: APA.

Stolurow, L. M. (1961). Teaching by machine. Washington: U.S. Department of Health, Education, and Welfare, Office of Education.

Taubman, P. M. (2009). Teaching by numbers: Deconstructing the discourse of standards and accountability in education. New York: Routledge.

Taylor, C. (1964). The explanation of behaviour. London: Routledge \& Kegan Paul.

Thorndike, E. L. (1898). Animal intelligence: An experimental study of the associative processes in animals. New York: Columbia University. 
Saari, A. (2019). Out of the box: behaviourism and the mangle of practice. Discourse: Studies in the Cultural Politics of Education, 40(1), 109-121.

Thorndike, E. L. (1912/1999). Education psychology. New York: Routledge.

Todd, J. T. (1994). What psychology has to say about John B. Watson: Classical behaviorism in psychology textbooks, 1920-1989. In J.T. Todd \& E.K. Morris (Eds.) Modern perspectives on John B. Watson and classical behaviorism (pp. 75-107) Westport: Greenwood.

Tröhler, D. (2013). The technocratic momentum after 1945, the development of teaching machines, and sobering results. Journal of Educational Media, Memory, and Society, 5(2), 119.

Waltz, S. B. (2004). Giving artifacts a voice? Bringing into account technology in educational analysis. Educational Theory, 54(2), 157-172.

Watson, J. B. (1913). Psychology as the behaviourist views it. Psychological Review, 20, $158-177$.

Watson, J. B., \& Rayner, R. (1920). Conditioned emotional reactions. Journal of Experimental Psychology 3 (1), 1-14.

Williamson, B. (2017). Decoding ClassDojo: psycho-policy, social-emotional learning and persuasive educational technologies. Learning, Media and Technology, 42(4), 440-453. 